\title{
Location Not Quantity of Blood Pressure Measurements Predicts Mortality in Hemodialysis Patients
}

\author{
Rajiv Agarwal Martin J. Andersen Robert P. Light \\ Indiana University School of Medicine and Richard L. Roudebush Veterans Administration Medical Center, \\ Indianapolis, Ind., USA
}

\section{Key Words \\ Blood pressure, self-measured · Ambulatory blood pressure $\cdot$ End-stage renal disease}

\begin{abstract}
Background: Blood pressure (BP) measurements obtained outside the dialysis unit are prognostically superior. Whether it is the greater number of measurements made outside the dialysis unit that correlates with prognosis or whether BPs outside dialysis units are ecologically more valid is unknown. Methods and Results: A prospective cohort study was conducted in 133 patients on chronic hemodialysis. BP was measured by the patients at home for 1 week, over an interdialytic interval by ambulatory recording, and by 'routine' and standardized methods in the dialysis unit for 2 weeks. Up to 6 BPs were randomly selected from a 44-hour recording of ambulatory or 1-week recording of home BPs, such that the dialysis unit BPs were exactly matched to the number of ambulatory or home BPs. The relationship with left ventricular hypertrophy and all-cause mortality was analyzed using receiver-operating characteristic curves and
\end{abstract}

Supported by grant 5RO1-063020-05 from the National Institutes of Health.

\section{KARGER \\ Fax +41613061234 \\ E-Mail karger@karger.ch}

(C) 2007 S. Karger AG, Basel

www.karger.com
Cox proportional hazards analysis, respectively. Over a median follow-up of 24 months, 46 patients (31\%) died. A BP change of $10 / 5 \mathrm{~mm} \mathrm{Hg}$ increased the risk of all-cause mortality by $1.22(95 \% \mathrm{Cl} 1.07-1.38) / 1.18(95 \% \mathrm{Cl} 1.05-1.31)$ with the average of the 44-hour recording and $1.20(95 \% \mathrm{Cl} 1.07-$ 1.34)/1.15 (95\% Cl 1.03-1.27) when up to 6 random BPs from the same ambulatory recording were drawn and averaged. With home BPs the hazard ratios were $1.17 / 1.15$ per $10 / 5 \mathrm{~mm}$ $\mathrm{Hg}$ increase in BP with the average of 1-week recording and 1.18/1.13 when up to 6 random BPs were drawn and averaged. Limited duration ambulatory BP monitoring of any 6hour interval during the first $24 \mathrm{~h}$ or 4 -day home BP recorded after the midweek dialysis was similarly predictive of allcause mortality. Conclusions: In patients on hemodialysis, the location, not the quantity, of the BP recordings obtained outside the dialysis unit is associated with target organ damage and mortality.

Copyright $\odot 2007$ S. Karger AG, Basel

\section{Introduction}

Blood pressure (BP) recorded in a physician's office or in the dialysis unit forms the basis of treatment for most hypertensive patients. However, in the general population [1-3], in patients with essential hypertension [4-6],

Rajiv Agarwal, MD

Indiana University and VAMC

1481 West 10th Street

Indianapolis, IN 46202 (USA)

Tel. +1 317988 2241, Fax +1 317988 2171, E-Mail ragarwal@iupui.edu 
and in those with chronic kidney disease $[7,8]$ ambulatory $\mathrm{BP}$ monitoring refines the diagnosis of hypertension in detecting the presence of white coat hypertension and masked hypertension. Therapy can therefore be appropriately directed to those who are truly hypertensive. However, ambulatory BP monitoring is cumbersome and self-measured home BP offers a practical alternative to managing patients with hypertension [9]. Indeed, selfmeasured home BP serves as a better prognostic tool compared to office $\mathrm{BP}$ recordings in the general population [10], in patients with treated hypertension [11] and in those with chronic kidney disease [12].

Although out-of-office BP measurements are better predictors of target organ damage and cardiovascular outcomes, it is unclear whether this is simply due to the greater number of measurements. For example, in hemodialysis patients nearly 100 ambulatory BP measurements were obtained over the 44-hour interdialytic period or 15 measurements were self-recorded at home over 1 week, which are far greater than the comparison group of 6 predialysis and 6 post-dialysis measurements that can be made over a 2-week period [13]. Obviously, averaging a greater number of out-of-dialysis unit BP measurements may provide a more reliable value. On the other hand, the validity of out-of-office BP measurements in predicting target organ damage or mortality may be greater than BPs obtained in the dialysis unit. Whether it is the greater number of recordings made outside the dialysis unit that correlates with prognosis or whether out-of-dialysis unit BPs are ecologically more valid is unknown.

In hemodialysis patients, at least one study by Zoccali et al. [14] has demonstrated that multiple BP recordings averaged over 1 month were able to predict the left ventricular (LV) mass index (LVMI) as well as ambulatory BP measurements. Another study in patients without kidney disease showed similar results [15]. Whether an identical number of self-measured home BPs or automatically recorded ambulatory BPs can predict target organ damage and prognosis better than BPs recorded in the dialysis unit is unknown.

We hypothesized that out-of-dialysis unit BP recordings, even when matched in number to BPs obtained in the dialysis unit, will be better predictors of target organ damage and all-cause mortality compared to BPs measured in the dialysis unit. We also tested the utility of a limited duration of ambulatory BP monitoring $(6,12$ or $24 \mathrm{~h}$ ) in determining all-cause mortality in hemodialysis patients.

\section{Participants and Methods}

Patients, aged 18 years or older, who had been on chronic hemodialysis for more than 3 months, were free of vascular, infectious or bleeding complications within 1 month of recruitment, and were dialyzed three times a week dialysis at one of the four dialysis units in Indianapolis affiliated with the Indiana University, were enrolled in the study. Those who missed two hemodialysis treatments or more over a month, abused drugs, had chronic atrial fibrillation or body mass index of $40 \mathrm{~kg} / \mathrm{m}^{2}$ or more were excluded. Patients who had a change in dry weight or antihypertensive drugs within 2 weeks were also excluded. The study was approved by the Institutional Review Board of Indiana University and the Research and Development Committee of the Roudebush VA Medical Center, Indianapolis, and all subjects gave written informed consent.

\section{Ambulatory BP Monitoring}

Ambulatory BP monitoring was performed after the midweek hemodialysis session for $44 \mathrm{~h}$. Ambulatory BPs were recorded every 20 min during the day (6 a.m. to 10 p.m.) and every 30 min during the night (10 p.m. to 6 a.m.) using a Spacelab 90207 ABP monitor (SpaceLabs Medical Inc, Redmond, Wash., USA) in the non-access arm, as reported previously [16]. Data were stored in a relational database and averages were calculated for systolic and diastolic pressures over the entire period of recording. Even a limited number of ambulatory BP is useful for prognostic purposes in the general population, therefore we did not exclude any patient based on the number of ambulatory BP recordings [17].

\section{Dialysis Unit BPs}

Dialysis unit BP recordings measured by the dialysis unit staff before and after dialysis were collected prospectively at the time of the patient visit. These BP recordings were obtained using the sphygmomanometer equipped with hemodialysis machines without a specified technique and were averaged over 2 weeks. Thus, each patient had 6 pre-dialysis and 6 post-dialysis BP recordings to provide the routine dialysis unit $\mathrm{BP}$.

$\mathrm{BP}$ was also recorded using a standard technique following an at least 5-min rest and using a validated oscillometric device (HEM 907, Omron Healthcare, Bannockburn, Ill., USA) by research nurses trained in this technique. Three readings at each visit were averaged to provide one recording. Pre-dialysis and post-dialysis recordings were averaged separately over 2 weeks to provide a standardized dialysis unit BP.

\section{Home BP Monitoring}

Home BP monitoring was performed over 1 week using a validated self-inflating automatic oscillometric device (HEM 705 $\mathrm{CP}$, Omron Healthcare). The protocol specified home BP monitoring in the first week. Patients were instructed in the use of this monitor and asked not to share this monitor with others. Patients were asked to record their BP three times daily (on waking up, between noon and 6 p.m. and at bedtime) and log this on a chart provided for this purpose. Since this monitor is equipped with a memory and printer, we used only those recordings that were recorded in the memory of the monitor. 


\section{Echocardiograms}

Two-dimensional guided M-mode echocardiograms were performed by one technician immediately after a mid-week hemodialysis session using a digital cardiac ultrasound machine (Cypress Acuson, Siemens Medical). The protocol specified recording of at least 12 cycles of 2-dimensional parasternal longand short-axis LV views with optimal orientation of the cursor beam used to derive additional M-mode recordings. The post-dialysis period was selected for echocardiography as it allows control over the volume state of the patient; the post-dialysis state is associated with the least intravascular volume. The day following dialysis would be associated with a variable change in the dimension of the ventricular cavity depending on the state of volume expansion and was not chosen for echocardiography. Each patient underwent six M-mode measurements of intraventricular septal thickness (IVSTd), LV internal diameter (LVIDd) and LV posterior wall thickness (LVPWd), all in diastole using the standards of the American Society of Echocardiography [18]. LV mass was calculated with a previously validated formula [19]:

$$
\begin{aligned}
& \text { LV mass }(g)= \\
& 0.832 \times\left[(\text { IVSTd }+ \text { LVIDd }+ \text { PWTd })^{3}-(\text { LVIDd })^{3}\right]+0.60
\end{aligned}
$$

LV mass was corrected for height ${ }^{2.7}$ measured in meters as it correlates better with long-term outcomes in dialysis patients [20] and recent studies have demonstrated that similar thresholds can be used for blacks and whites [21]. $\mathrm{LV}$ mass $>51 \mathrm{~g} / \mathrm{m}^{2.7}$ was taken as evidence of LVH.

To analyze the sensitivity and specificity of hemodialysis unit $\mathrm{BPs}$ in relationship to LV hypertrophy $(\mathrm{LVH})$ we generated receiver-operating characteristic (ROC) curves, including the area under the curve and their 95\% confidence intervals [22].

\section{Data Reduction}

We counted the number of standardized, routine, home, and ambulatory BP measurements for every hemodialysis patient. The BP method with the lowest number of recordings was used to determine the number of BP measurements to be analyzed. For example, if a patient had only five standardized BP recordings, then only five routine, standardized, home, and ambulatory blood measurements were analyzed. Ambulatory and home BPs were selected at random over the 44-hour interdialytic period and week, respectively. The mean systolic or diastolic BP from every method was used to predict the endpoint of death.

There were 12 patients who had fewer home BP measurements than both the standardized and routine BPs. In these patients, we limited the standardized, routine, and ambulatory recordings to the number of home BP recordings. There were 2 patients who had fewer ambulatory BP measurements than both the standardized, routine or home BPs. In these patients, ambulatory recordings were the limiting factor. For example, if a patient only recorded two ambulatory BPs then only two dialysis unit and two home BP were analyzed. BP obtained in the dialysis unit was also selected at random after stratification for predialysis or post-dialysis measurement time. As above, the ambulatory BPs were selected at random over the 44-hour interdialytic period. Those patients without any ambulatory or home BP data were excluded.

Original oscillometric data from each BP series were first synchronized for each individual by re-computing all times of sam- pling in hours from end of dialysis to avoid differences among subjects dialyzing on different dialysis shifts. We averaged each series in four 6-hour blocks, two 12-hour blocks and one 24-hour block over the first $24 \mathrm{~h}$ from the end of dialysis. Home BPs were analyzed according to the day of the week centered about the first dialysis.

\section{Data Analysis}

Cox proportional hazards regression was used to determine the significance and strength of association of factors associated with mortality. The proportionality assumption was tested by evaluating the log minus log plot. Hazard ratios and 95\% confidence intervals were calculated from the proportional hazards model regression coefficients and their standard errors for $10 / 5$ $\mathrm{mm} \mathrm{Hg}$ change in systolic/diastolic BP. Because all BPs were obtained in the same population the hazard ratios were not adjusted for the comparisons.

All analyses were conducted using SPSS Software version 14.0 (SPSS Inc, Chicago, Ill., USA). The p values reported are twosided and taken to be significant at $<0.05$.

\section{Results}

Between September 2003 and February 2005 we recruited 150 patients from four dialysis units staffed by the nephrology faculty of the Indiana University, Indianapolis. The diagnostic performance of various BPs in this cohort has been previously published [13]. Seventeen patients who did not have at least one record of each BP (dialysis unit, ambulatory or home) were excluded.

The clinical characteristics of the remaining 133 patients are shown in table 1 . The population was predominantly black with an average age of 57 years. All patients were on thrice weekly dialysis and were prescribed a dialysis time of about $4 \mathrm{~h}$, blood flow rate of $400 \mathrm{ml} / \mathrm{min}$, and dialysate flow rate of $750 \mathrm{ml} / \mathrm{min}$. The average urea reduction ratio, serum albumin and hemoglobin were within the recommended range for hemodialysis patients. Cardiovascular disease, defined as a previous history of myocardial infarction, coronary or vascular bypass surgery or angioplasty, stroke, aortic aneurysm or non-traumatic amputation, was present in $49 \%$ patients. The majority of the patients $(83 \%)$ received antihypertensive drugs, with an average of 2.4 drugs in those who took them (table 2). $\beta$-Blockers were the most commonly utilized antihypertensive agent, followed by ACE inhibitors.

The median follow-up was 24 (inter-quartile range 16-32) months. During this follow-up period 46 (31\%) patients died, of which 26 (57\% of all-cause deaths) were cardiovascular causes. The crude mortality rate was $157 / 1,000$ patient-years, with a cardiovascular mortality 
Table 1. Clinical characteristics of the study population $(\mathrm{n}=133)$

\begin{tabular}{lc}
\hline Clinical characteristics & \\
\hline Age, years & $56.8 \pm 12.9$ \\
Men, $\mathrm{n}$ & $85(64 \%)$ \\
Race & \\
$\quad$ White, $\mathrm{n}$ & $11(8 \%)$ \\
$\quad$ Black, $\mathrm{n}$ & $20(90 \%)$ \\
$\quad$ Other, $\mathrm{n}$ & $2(2 \%)$ \\
Pre-dialysis weight, kg & $78.6 \pm 18.8$ \\
Post-dialysis weight, kg & $26.7 \pm 6.2$ \\
BMI, kg/m ${ }^{2}$ & $4.0 \pm 3.0$ \\
Years of dialysis & \\
Etiology of end-stage renal disease & $43(32 \%)$ \\
$\quad$ Diabetes mellitus, $\mathrm{n}$ & $74(56 \%)$ \\
$\quad$ Hypertension, $\mathrm{n}$ & $7(5 \%)$ \\
$\quad$ Glomerulonephritis, $\mathrm{n}$ & $1(<1 \%)$ \\
$\quad$ Obstruction, $\mathrm{n}$ & $8(6 \%)$ \\
$\quad$ Other, $\mathrm{n}$ & $50(38 \%)$ \\
Current smoker, $\mathrm{n}$ & $65(49 \%)$ \\
Cardiovascular disease, $\mathrm{n}$ & $73 \pm 7.6$ \\
Urea reduction ratio & $3.8 \pm 0.4$ \\
Albumin, g/dl & $12.5 \pm 1.5$ \\
Hemoglobin, g/dl & \\
\hline
\end{tabular}

Values are mean \pm SD unless otherwise indicated.

Table 2. Antihypertensive drug use and BP measurements

\begin{tabular}{|c|c|}
\hline Number receiving antihypertensive drugs & $110(83 \%)$ \\
\hline Number of antihypertensives in users & $2.4 \pm 1.2$ \\
\hline \multicolumn{2}{|l|}{ Nature of antihypertensive agent } \\
\hline Dihydropyridine calcium channel blockers & $45(41 \%)$ \\
\hline $\begin{array}{l}\text { Non-dihydropyridine calcium-channel } \\
\text { blockers }\end{array}$ & $6(5 \%)$ \\
\hline$\beta$-Blockers & $82(75 \%)$ \\
\hline$\alpha$-Blockers & $7(6 \%)$ \\
\hline Centrally acting agents & $27(25 \%)$ \\
\hline Vasodilators & $19(17 \%)$ \\
\hline ACE inhibitors & $54(49 \%)$ \\
\hline Angiotensin receptor blockers & $20(18 \%)$ \\
\hline 44-hour ambulatory $\mathrm{BP}, \mathrm{mm} \mathrm{Hg}$ & $129.2 \pm 22.5 / 73.3 \pm 13.9$ \\
\hline Home BP, mm Hg & $142.3 \pm 22.5 / 80.0 \pm 13.3$ \\
\hline \multicolumn{2}{|l|}{ Standardized BP, $\mathrm{mm} \mathrm{Hg}$} \\
\hline Pre-dialysis & $143.0 \pm 22.7 / 74.7 \pm 13.8$ \\
\hline Post-dialysis & $121.3 \pm 21.4 / 69.6 \pm 13.2$ \\
\hline \multicolumn{2}{|l|}{ Routine BP, mm Hg } \\
\hline Pre-dialysis & $146.6 \pm 22.0 / 79.7 \pm 13.3$ \\
\hline Post-dialysis & $132.9 \pm 20.2 / 73.1 \pm 11.6$ \\
\hline
\end{tabular}

Values are mean \pm SD unless otherwise indicated.
Table 3. Receiver-operating characteristic (ROC) curves for diagnosing left ventricular hypertrophy

\begin{tabular}{lcl}
\hline & \multicolumn{2}{c}{ Area under systolic ROC curve } \\
\cline { 2 - 3 } & $\begin{array}{c}\text { full data } \\
(95 \% \mathrm{CI})^{\mathrm{a}}\end{array}$ & $\begin{array}{l}\text { random matched data } \\
(95 \% \mathrm{CI})^{\mathrm{a}}\end{array}$ \\
\hline Routine dialysis unit blood pressure & \\
Pre-HD & $0.63(0.53-0.74)$ & $0.63(0.52-0.73)$ \\
Post-HD & $0.61(0.51-0.71)$ & $0.61(0.50-0.71)$ \\
Standardized dialysis unit blood pressure & \\
$\quad$ Pre-HD & $0.64(0.53-0.74)$ & $0.65(0.54-0.75)$ \\
Post-HD & $0.60(0.49-0.70)$ & $0.57(0.47-0.68)$ \\
Home blood pressure & $0.69(0.60-0.79)$ & $0.71(0.61-0.80)$ \\
44-hour ambulatory BP & $0.64(0.54-0.74)$ & $0.62(0.53-0.72)$ \\
\hline
\end{tabular}

a All areas under the ROC curve were significant except postdialysis standardized at $\mathrm{p}<0.05$. The home systolic blood pressure area under the ROC curve was significant at $\mathrm{p}<0.0001$.

rate of 89/1,000 patient-years. Causes of cardiovascular death were sudden cardiac death $(\mathrm{n}=14)$, myocardial infarction $(\mathrm{n}=6)$, pulmonary edema $(\mathrm{n}=2)$ and stroke $(\mathrm{n}=3)$.

Table 3 shows the ROC curve performance of systolic $\mathrm{BPs}$ for diagnosing LVH. The strongest relationship was achieved with home BP monitoring, followed by ambulatory BP. Although dialysis unit BPs were generally predictive of $\mathrm{LVH}$, the relationship was weak or nonexistent for standardized dialysis unit post-dialysis BPs. A randomly selected limited number of BPs predicted LVH nearly as well as the more complete data set. Thus, the area under curve of ROC with the full set of data with ambulatory BP was 0.64 and similar at 0.62 with only 6 BPs. Diastolic BPs were not predictive of LVH (data not shown).

Table 4 shows the hazard ratios for mortality of the various BP-monitoring techniques. Since the standard deviations of systolic BPs were similar across the techniques and approximately twice that of diastolic BPs, the hazard ratios are reported for a $10 / 5 \mathrm{~mm} \mathrm{Hg}$ change in systolic and diastolic BP. BPs obtained in the dialysis unit were of limited significance for their prognostic value in predicting mortality. Only post-dialysis systolic BPs predicted mortality. There were between 15 and $17 \%$ increases in mortality for every $10 \mathrm{~mm} \mathrm{Hg}$ increase in systolic BP. Ambulatory and home BP recordings on the other hand had prognostic information contained in both systolic and diastolic BPs. All-cause mortality was 22/18\% higher in patients who had a systolic/diastolic increase in $\mathrm{BP}$ of $10 / 5 \mathrm{~mm} \mathrm{Hg}$. When just 6 random BPs were picked

Am J Nephrol 2008;28:210-217 
Table 4. Hazard ratios for all-cause mortality associated with the technique of blood pressure monitoring

\begin{tabular}{|c|c|c|c|c|c|c|c|c|c|c|c|c|}
\hline & \multicolumn{6}{|c|}{ Full data set } & \multicolumn{6}{|c|}{ Randomly matched data set ${ }^{\mathrm{a}}$} \\
\hline & \multicolumn{3}{|c|}{ systolic blood pressure } & \multicolumn{3}{|c|}{ diastolic blood pressure } & \multicolumn{3}{|c|}{ systolic blood pressure } & \multicolumn{3}{|c|}{ diastolic blood pressure } \\
\hline & $\begin{array}{l}\text { HR per } \\
10 \mathrm{~mm} \mathrm{H}\end{array}$ & $95 \%$ CI & $\mathrm{p}$ & $\begin{array}{l}\text { HR per } \\
5 \mathrm{~mm} \mathrm{Hg}\end{array}$ & $95 \%$ CI & $\mathrm{p}$ & $\begin{array}{l}\text { HR per } \\
10 \mathrm{~mm} \mathrm{Hg}\end{array}$ & $95 \%$ CI & $\mathrm{p}$ & $\begin{array}{l}\text { HR per } \\
5 \mathrm{~mm} \mathrm{Hg}\end{array}$ & $95 \%$ CI & $\mathrm{p}$ \\
\hline \multicolumn{13}{|c|}{ Routine dialysis unit } \\
\hline Pre-dialysis & 1.05 & $0.92-1.20$ & 0.5 & 1.02 & $0.91-1.15$ & 0.697 & 1.06 & $0.92-1.21$ & 0.438 & 1.04 & $0.93-1.16$ & 0.543 \\
\hline Post-dialysis & 1.17 & $1-1.37$ & 0.043 & 1.06 & $0.93-1.21$ & 0.398 & 1.17 & $1-1.36$ & 0.049 & 1.06 & $0.93-1.20$ & 0.41 \\
\hline \multicolumn{13}{|c|}{ Standardized dialysis unit } \\
\hline Pre-dialysis & 1.13 & $0.99-1.30$ & 0.073 & 1.05 & $0.94-1.18$ & 0.407 & 1.1 & $0.97-1.25$ & 0.131 & 1.04 & $0.93-1.16$ & 0.481 \\
\hline Post-dialysis & 1.16 & $1.01-1.33$ & 0.035 & 1.02 & $0.91-1.15$ & 0.69 & 1.15 & $1-1.31$ & 0.042 & 1.04 & $0.93-1.16$ & 0.488 \\
\hline Home & 1.17 & $1.02-1.35$ & 0.026 & 1.15 & $1.02-1.30$ & 0.022 & 1.18 & $1.03-1.34$ & 0.014 & 1.13 & $1-1.26$ & 0.042 \\
\hline Ambulatory & 1.22 & $1.07-1.38$ & 0.002 & 1.18 & $1.05-1.31$ & 0.005 & 1.2 & $1.07-1.34$ & 0.002 & 1.15 & $1.03-1.27$ & 0.009 \\
\hline
\end{tabular}

$\mathrm{HR}=$ Hazard ratio; $\mathrm{CI}=$ confidence interval.

a The number of recordings for any one patient were equal for any blood pressure-monitoring technique.

Table 5. Hazard ratios for all-cause mortality associated with limited duration ambulatory blood pressure monitoring

\begin{tabular}{|c|c|c|c|c|c|c|c|c|c|}
\hline \multirow{2}{*}{$\begin{array}{l}\text { Duration of ambulatory } \\
\text { monitoring }\end{array}$} & \multirow{2}{*}{$\begin{array}{l}\text { Number } \\
\text { of BPs }\end{array}$} & \multirow[t]{2}{*}{ Mean \pm SD } & \multicolumn{3}{|c|}{ Systolic blood pressure } & \multirow[t]{2}{*}{ Mean \pm SD } & \multicolumn{3}{|c|}{ Diastolic blood pressure } \\
\hline & & & $\begin{array}{l}\text { HR per } \\
10 \mathrm{~mm} \mathrm{Hg}\end{array}$ & ${ }_{\mathrm{g}}^{95 \% \mathrm{CI}}$ & $\mathrm{p}$ & & $\begin{array}{l}\text { HR per } \\
5 \mathrm{~mm} \mathrm{Hg}\end{array}$ & $95 \% \mathrm{CI}$ & $\mathrm{p}$ \\
\hline Interdialytic 44 -hour & $92 \pm 26$ & $129.2 \pm 22.5$ & 1.22 & $1.07-1.38$ & 0.002 & $73.3 \pm 13.9$ & 1.18 & $1.05-1.31$ & 0.005 \\
\hline First $24 \mathrm{~h}$ post-dialysis & $53 \pm 15$ & $126.9 \pm 23.0$ & 1.25 & $1.10-1.41$ & 0.001 & $72.4 \pm 14.2$ & 1.18 & $1.06-1.32$ & 0.002 \\
\hline First $12 \mathrm{~h}$ post-dialysis & $29 \pm 8$ & $125.6 \pm 11.7$ & 1.25 & $1.09-1.43$ & 0.001 & $72.0 \pm 14.4$ & 1.15 & $1.04-1.28$ & 0.010 \\
\hline Second $12 \mathrm{~h}$ post-dialysis & $26 \pm 6$ & $128.3 \pm 24.6$ & 1.23 & $1.09-1.38$ & 0.001 & $72.7 \pm 15.1$ & 1.21 & $1.10-1.34$ & $<0.0001$ \\
\hline First $6 \mathrm{~h}$ post-dialysis & $16 \pm 5$ & $126.0 \pm 22.4$ & 1.23 & $1.08-1.41$ & 0.002 & $72.9 \pm 14.3$ & 1.14 & $1.03-1.26$ & 0.014 \\
\hline Second $6 \mathrm{~h}$ post-dialysis & $14 \pm 3$ & $124.8 \pm 24.7$ & 1.23 & $1.08-1.40$ & 0.002 & $70.8 \pm 15.7$ & 1.15 & $1.04-1.28$ & 0.008 \\
\hline Third $6 \mathrm{~h}$ post-dialysis & $12 \pm 2$ & $126.2 \pm 24.7$ & 1.25 & $1.10-1.41$ & $<0.0001$ & $70.4 \pm 15.0$ & 1.22 & $1.10-1.35$ & $<0.0001$ \\
\hline Fourth $6 \mathrm{~h}$ post-dialysis & $14 \pm 4$ & $130.0 \pm 25.4$ & 1.19 & $1.06-1.34$ & 0.004 & $74.4 \pm 15.8$ & 1.19 & $1.08-1.31$ & 0.001 \\
\hline
\end{tabular}

$\mathrm{BPs}=$ Blood pressure recordings; $\mathrm{HR}=$ hazard ratio; $\mathrm{CI}=$ confidence interval.

from the 44-hour record and examined for their relationship with all-cause mortality, 20/15\% higher mortality was seen. Home BPs were associated with $17 / 15 \%$ increase in mortality that was similar at $18 / 13 \%$ when a limited number of random home BPs was used.

Table 5 demonstrates the relationship between a limited duration of ambulatory BP monitoring and the hazard ratio for all-cause mortality. Using the full 44-hour recording, an increase in mortality rate of $22 / 18 \%$ was seen. Similar hazard ratios were observed whether the first $24 \mathrm{~h}$ of recording, 12-hour recording or any 6-hour averaged recording was used.

Figure 1 demonstrates the hazard ratios associated with limited home BP averages by the day of dialysis. Neither an individual non-dialysis period nor the combina- tion of dialysis days was predictive of all-cause mortality. The hazard ratio for the combination of the 3 dialysis days was 1.14 for a $10 \mathrm{~mm} \mathrm{Hg}$ change in systolic and 1.11 for a $5 \mathrm{~mm} \mathrm{Hg}$ change in diastolic BP. BP monitoring performed on the first interdialytic day when combined with any or all of the interdialytic days failed to be of prognostic significance. Removing the first interdialytic day BP recording from the remaining interdialytic days added prognostic information to the recordings. BP monitoring starting after the mid-week dialysis and ending just before the first dialysis of the week also improved the prognostic significance. The hazard ratio for the combination of the 4 days after the mid-week dialysis was 1.13 for 10 $\mathrm{mm} \mathrm{Hg}$ change in systolic and 1.12 for $5 \mathrm{~mm} \mathrm{Hg}$ change in diastolic BP. 


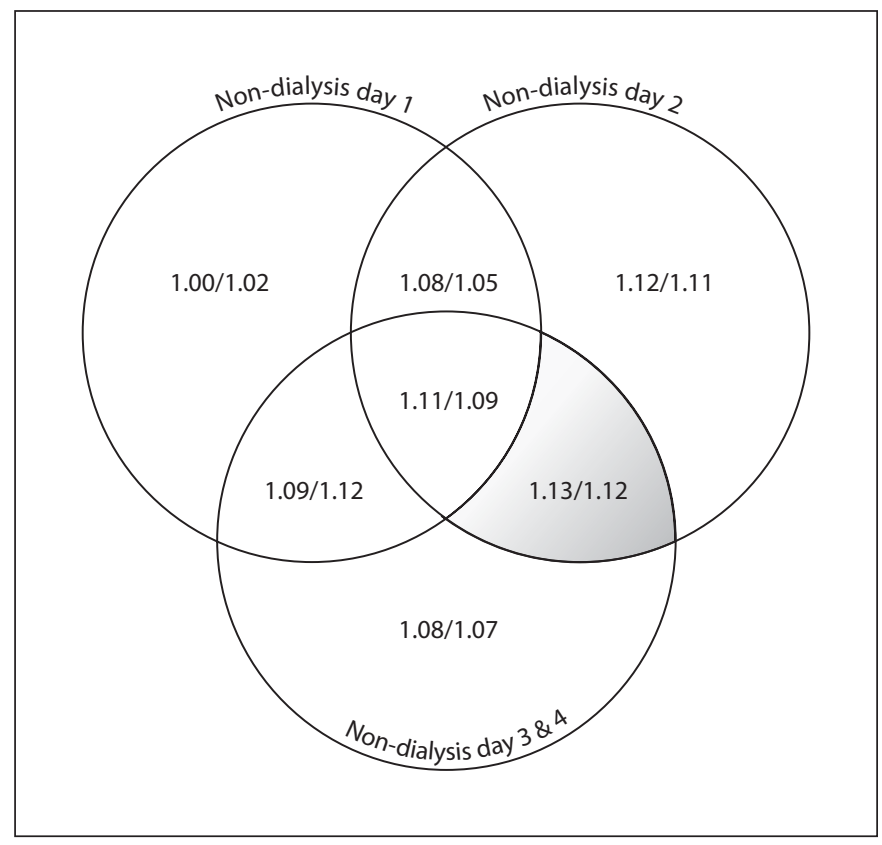

Fig. 1. Relationship of mortality with home blood pressure monitoring obtained on various non-dialysis days. The circles represent the non-dialysis days. Non-dialysis days 3 and 4 represent the weekend. A combination of days (non-dialysis days 2 and over weekend) was statistically significant and is shaded.

\section{Discussion}

There are four important results contained in this report. First, target organ damage can be predicted as well by a limited number of randomly sampled BPs from a 44hour ambulatory recording or 1-week home BP recording. Second, the prognostic information contained in BPs obtained outside the dialysis unit is not dependent on a greater number of the $\mathrm{BP}$ recordings. Third, limited duration ambulatory $\mathrm{BP}$ monitoring can predict all-cause mortality nearly as well as more cumbersome interdialytic BP recording. Fourth, a 3- to 4-day home BP record obtained three times a day after a mid-week dialysis contains prognostic information.

We have previously demonstrated that there is little relationship between BPs obtained in the dialysis unit with $\mathrm{LVH}$, but a stronger relationship is seen between BPs obtained outside the dialysis unit and LVH [23]. The results of this study show that the stronger relationship is not due to the greater number of BP recordings obtained outside the dialysis unit. We have also previously reported that home and ambulatory BP recordings are of

Limited BP Sampling in Hemodialysis direct prognostic significance [24]. The results of this study extend the previous observations that the prognostic value is simply not due to the greater number of measurements.

We asked patients to record BP three times a day for 1 week, but it was unclear if a 1-week duration was necessary to obtain prognostic information. In fact, our data demonstrate that omitting the BP recordings until the mid-week dialysis did not adversely affect the prognostic value of the recordings. The first interdialytic day did not contain prognostic information. BPs obtained after the mid-week dialysis including the weekend may be a better representation of ambient BPs. Although similar studies on the appropriate duration of $\mathrm{BP}$ monitoring in patients with chronic kidney disease are not available, in patients with essential hypertension 2 days of home BPs obtained at least in twice a day was found sufficient to provide a reliable estimate $[25,26]$. Some investigators have reported that the first day of recording gave a higher $\mathrm{BP}$ recording and that deleting the first day of home BP measurements may increase reproducibility [26].

Interdialytic 44-hour ambulatory BP monitoring is cumbersome and it is not clear if less intense periods of monitoring may provide the same prognostic information. In fact, we found that as little as $6 \mathrm{~h}$ of ambulatory $\mathrm{BP}$ recording was sufficient for prognostic purposes. These 6-hour periods contained at least 12 recorded BPs on average which is the minimum number recommended by the European Society of Hypertension for an adequate ambulatory $\mathrm{BP}$ record [27].

Although a similar study that links end-stage renal disease mortality to matched numbers of dialysis unit, home and ambulatory BPs is not available for comparison, the results of our study are consistent with a previously published cross-sectional study examining the association of matched numbers of ambulatory BPs and clinic BPs with LVH. Gerin et al. [17] found that using multiple regression analysis, including both ambulatory and physician BP measurements, only the ambulatory systolic measurement significantly predicted LVMI. Furthermore, a similar strength of the association between LVMI and ambulatory BP was seen when just three readings were randomly picked from the latter recordings. Although the reasons for the greater predictive power in out-of-dialysis unit BPs is not known, it is possible, as suggested by Gerin et al. [17], that BPs sampled from a broader pool of situations may make them more representative of the person's typical BP. Furthermore, dialysis unit BPs may be influenced by the white coat effect (elevated $\mathrm{BP}$ only in the dialysis setting) which may be less 
pronounced with home BPs and eliminated by ambulatory $\mathrm{BP}$ monitoring [28]. Also, masked hypertension (elevated $\mathrm{BP}$ at home but normal in the dialysis unit) is potentially detected with home BP monitoring and ambulatory $\mathrm{BP}$ monitoring and may be of prognostic significance [29].

There are several strengths and limitations of our work. Our study was largely limited to black people dialyzed in a few dialysis units, and we excluded certain patients such as those with morbid obesity and atrial fibrillation due to difficulties with accurate BP assessment in this group. Whether the same results would hold in people of other ethnicities and of broader clinical characteristics is not known. The sample size of our study was relatively small, yet the statistical significance of the prognostic information contained in ambulatory and home $\mathrm{BP}$ recordings are amongst the first reported in this population. The home BP monitor we used was a validated unit equipped with a memory device and printer, so there was a mechanism in place to confirm the authenticity of the patient reports [30].

In conclusion, dialysis unit BPs are unreliable predictors of ambulatory BP, target organ damage and all-cause mortality in hemodialysis patients. Even a limited number of home BP measurements and a limited duration of ambulatory BP recordings can provide prognostic information that cannot be ascertained even from a large number of BPs obtained in the dialysis unit. The location, not the quantity, of recordings made outside the dialysis unit appears to better reflect the true BP, since these recordings are better associated both with greater target organ damage as well as all-cause mortality. Home BP monitoring and potentially limited ambulatory BP monitoring should be more widely deployed to assess cardiovascular risk in hemodialysis patients.

\section{References}

- Ohkubo T, Imai Y, Tsuji I, Nagai K, Watanabe N, Minami N, Itoh O, Bando T, Sakuma M, Fukao A, Satoh H, Hisamichi S, Abe K: Prediction of mortality by ambulatory blood pressure monitoring versus screening blood pressure measurements: a pilot study in Ohasama. J Hypertens 1997;15:357-364.

$\checkmark 2$ Ohkubo T, Hozawa A, Nagai K, Kikuya M, Tsuji I, Ito S, Satoh H, Hisamichi S, Imai Y: Prediction of stroke by ambulatory blood pressure monitoring versus screening blood pressure measurements in a general population: the Ohasama study. J Hypertens 2000; 18:847-854.

-3 Kikuya M, Ohkubo T, Asayama K, Metoki H, Obara T, Saito S, Hashimoto J, Totsune K, Hoshi H, Satoh H, Imai Y: Ambulatory blood pressure and 10-year risk of cardiovascular and noncardiovascular mortality: the Ohasama study. Hypertension 2005;45:240245.

$\checkmark 4$ Clement DL, De Buyzere ML, De Bacquer DA, de Leeuw PW, Duprez DA, Fagard RH, Gheeraert PJ, Missault LH, Braun JJ, Six RO, Van Der NP, O’Brien E: Prognostic value of ambulatory blood-pressure recordings in patients with treated hypertension. $\mathrm{N}$ Engl J Med 2003;348:2407-2415.

$\checkmark 5$ Dolan E, Stanton A, Thijs L, Hinedi K, Atkins N, McClory S, Den Hond E, McCormack P, Staessen JA, O’Brien E: Superiority of ambulatory over clinic blood pressure measurement in predicting mortality: the Dublin outcome study. Hypertension 2005; 46:156-161.
6 Staessen JA, Thijs L, Fagard R, O’Brien ET, Clement D, de Leeuw PW, Mancia G, Nachev C, Palatini P, Parati G, Tuomilehto J, Webster J: Predicting cardiovascular risk using conventional vs. ambulatory blood pressure in older patients with systolic hypertension. Systolic Hypertension in Europe Trial Investigators. JAMA 1999;282:539-546.

-7 Agarwal R, Andersen MJ: Prognostic importance of ambulatory blood pressure recordings in patients with chronic kidney disease. Kidney Int 2006;69:1175-1180.

8 Thompson AM, Pickering TG: The role of ambulatory blood pressure monitoring in chronic and end-stage renal disease. Kidney Int 2006;70:1000-1007.

$\checkmark 9$ Pickering TG, Hall JE, Appel LJ, Falkner BE, Graves J, Hill MN, Jones DW, Kurtz T, Sheps SG, Roccella EJ: Recommendations for blood pressure measurement in humans and experimental animals. Part 1: blood pressure measurement in humans: a statement for professionals from the Subcommittee of Professional and Public Education of the American Heart Association Council on High Blood Pressure Research. Hypertension 2005;45:142-161.

10 Ohkubo T, Imai Y, Tsuji I, Nagai K, Kato J, Kikuchi N, Nishiyama A, Aihara A, Sekino M, Kikuya M, Ito S, Satoh H, Hisamichi S: Home blood pressure measurement has a stronger predictive power for mortality than does screening blood pressure measurement: a population-based observation in Ohasama, Japan. J Hypertens 1998;16:971975.
1 Bobrie G, Chatellier G, Genes N, Clerson P, Vaur L, Vaisse B, Menard J, Mallion JM: Cardiovascular prognosis of 'masked hypertension' detected by blood pressure self-measurement in elderly treated hypertensive patients. JAMA 2004;291:1342-1349.

12 Agarwal R, Andersen MJ: Prognostic importance of clinic and home blood pressure recordings in patients with chronic kidney disease. Kidney Int 2006;69:406-411.

13 Agarwal R, Andersen MJ, Bishu K, Saha C: Home blood pressure monitoring improves the diagnosis of hypertension in hemodialysis patients. Kidney Int 2006;69:900-906.

14 Zoccali C, Mallamaci F, Tripepi G, Benedetto FA, Cottini E, Giacone G, Malatino L: Prediction of left ventricular geometry by clinic, pre-dialysis and 24-hour ambulatory BP monitoring in hemodialysis patients: CREED investigators. J Hypertens 1999;17: 1751-1758.

15 Fagard RH, Staessen JA, Thijs L: Prediction of cardiac structure and function by repeated clinic and ambulatory blood pressure. Hypertension 1997;29:22-29.

16 Agarwal R: Supervised atenolol therapy in the management of hemodialysis hypertension. Kidney Int 1999;55:1528-1535.

17 Gerin W, Schwartz JE, Devereux RB, Goyal T, Shimbo D, Ogedegbe G, Rieckmann N, Abraham D, Chaplin W, Burg M, Jhulani J, Pickering TG: Superiority of ambulatory to physician blood pressure is not an artifact of differential measurement reliability. Blood Press Monit 2006;11:297-301. 
18 Sahn DJ, DeMaria A, Kisslo J, Weyman A: Recommendations regarding quantitation in M-mode echocardiography: results of a survey of echocardiographic measurements. Circulation 1978;58:1072-1083.

19 Devereux RB, Alonso DR, Lutas EM, Gottlieb GJ, Campo E, Sachs I, Reichek N: Echocardiographic assessment of left ventricular hypertrophy: comparison to necropsy findings. Am J Cardiol 1986;57:450-458.

-20 Zoccali C, Benedetto FA, Mallamaci F, Tripepi G, Giacone G, Cataliotti A, Seminara G, Stancanelli B, Malatino LS: Prognostic impact of the indexation of left ventricular mass in patients undergoing dialysis. J Am Soc Nephrol 2001;12:2768-2774.

-21 Nunez E, Arnett DK, Benjamin EJ, Liebson PR, Skelton TN, Taylor H, Andrew M: Optimal threshold value for left ventricular hypertrophy in blacks: the Atherosclerosis Risk in Communities study. Hypertension 2005; 45:58-63.
22 Zweig MH, Campbell G: Receiver-operating characteristic (ROC) plots: a fundamental evaluation tool in clinical medicine. Clin Chem 1993;39:561-577. Erratum in Clin Chem 1993;39:1589.

23 Agarwal R, Brim NJ, Mahenthiran J, Andersen MJ, Saha C: Out-of-hemodialysis-unit blood pressure is a superior determinant of left ventricular hypertrophy. Hypertension 2006;47:62-68.

24 Alborzi P, Patel N, Agarwal R: Home blood pressures are of greater prognostic value than hemodialysis unit recordings. Clin J Am Soc Nephrol 2007;2:1228-1234.

25 Mallion JM, Genes N, Vaur L, Clerson P, Vaisse B, Bobrie G, Chatellier G: Detection of masked hypertension by home blood pressure measurement: is the number of measurements an important issue? Blood Press Monit 2004;9:301-305.

26 Stergiou GS, Skeva II, Zourbaki AS, Mountokalakis TD: Self-monitoring of blood pressure at home: how many measurements are needed? J Hypertens 1998;16:725-731.
27 O’Brien E, Asmar R, Beilin L, Imai Y, Mallion JM, Mancia G, Mengden T, Myers M, Padfield P, Palatini P, Parati G, Pickering T, Redon J, Staessen J, Stergiou G, Verdecchia P: European Society of Hypertension recommendations for conventional, ambulatory and home blood pressure measurement. J Hypertens 2003;21:821-848.

28 Thijs L, Staessen JA, Celis H, Fagard R, De Cort P, de Gaudemaris R, Enstrom I, Imai Y, Julius S, Menard J, Mion D, Palatini P, Rosenfeld J, Shapiro D, Spence D, Stergiou G: The international database of self-recorded blood pressures in normotensive and untreated hypertensive subjects. Blood Press Monit 1999; 4:77-86.

29 Andersen MJ, Khawandi W, Agarwal R: Home blood pressure monitoring in CKD. Am J Kidney Dis 2005;45:994-1001.

30 Johnson KA, Partsch DJ, Rippole LL, McVey DM: Reliability of self-reported blood pressure measurements. Arch Intern Med 1999; 159:2689-2693. 